\title{
Genetic parameters for test day milk yields of first lactation Holstein cows by random regression models
}

\author{
C. M. R. de Melo ${ }^{1 \dagger}$, I. U. Packer $^{2}$, C. N. Costa $^{3}$ and P. F. Machado ${ }^{2}$ \\ ${ }^{1}$ Aqüiculture Department - AQI/UFSC, 88040-900 Florianópolis/SC, Brazil; ${ }^{2}$ Animal Science Departament - USP/ESALQ, $13418-900$ Piracicaba/SP, Brazil \\ ${ }^{3}$ Embrapa Gado de Leite, 36038-330 Juiz de Fora/MG, Brazil
}

(Received 6 June 2006; Accepted 15 December 2006)

Covariance components for test day milk yield using 263390 first lactation records of 32448 Holstein cows were estimated using random regression animal models by restricted maximum likelihood. Three functions were used to adjust the lactation curve: the five-parameter logarithmic Ali and Schaeffer function (AS), the three-parameter exponential Wilmink function in its standard form $(W)$ and in a modified form $\left(W^{*}\right)$, by reducing the range of covariate, and the combination of Legendre polynomial and $W$ $(L E G+W)$. Heterogeneous residual variance (RV) for different classes (4 and 29) of days in milk was considered in adjusting the functions. Estimates of $R V$ were quite similar, rating from 4.15 to $5.29 \mathrm{~kg}^{2}$. Heritability estimates for AS (0.29 to 0.42$)$, LEG $+W$ ( 0.28 to 0.42$)$ and $W^{*}(0.33$ to 0.40$)$ were similar, but heritability estimates used $W(0.25$ to 0.65$)$ were highest than those estimated by the other functions, particularly at the end of lactation. Genetic correlations between milk yield on consecutive test days were close to unity, but decreased as the interval between test days increased. The AS function with homogeneous RV model had the best fit among those evaluated.

Keywords: genetic parameters, milk yield, random regression model, test day model, variance components

\section{Introduction}

Test day models (TDM) have been receiving considerable attention from research studies on the genetic improvement of dairy cattle (Gengler et al., 1999; Kettunen et al., 2000; Schaeffer et al., 2000; Swalve, 2000; Misztal et al., 2000; Jensen, 2002; Lopez-Romero and Carabaño, 2003; Mrode and Swanson, 2004; Fischer et al., 2004; Schaeffer, 2004; Albuquerque and Meyer, 2005). The use of TDM allows a more accurate definition of contemporary groups (CG) and associated environmental effects, thus offering a more specific definition of the effects of the lactation stage and reproduction of dairy cows. Further characteristics associated with TDM include the use of additional information on a single animal during genetic evaluations, a better adjustment for lactation of different durations and the possibility of adjusting for individual differences in the shape of a lactation curve, which permits the assessment of lactation persistence (Jakobsen et al., 2002). Perhaps the most important use of TDM is that it makes possible the assessment of animals with lactations in progress, allowing for more frequent assessments and, thus, a

\footnotetext{
${ }^{\dagger}$ E-mail: cmrmelo@cca.ufsc.br
}

reduction in the generation interval (Swalve, 1998 and 2000; Jensen, 2002).

Different models have been described for the adjustment of TDM (Misztal et al., 2000; Swalve, 2000; Jensen, 2002). Random regression models (RRM) allow the modeling of the covariance structure among test day yields. They avoid the simplicity associated to repeatability models, which assume a correlation equal to unity and variance homogeneous among the yields, as well as the computational complexity associated to multiple character models, due to the great number of parameters that need to be estimated (Meyer, 1998b, Misztal et al., 2000: Swalve, 2000).

The potential advantages associated with TDM have led researchers from various countries to investigate the implementation of these procedures in national genetic evaluation systems (Swalve, 2000; Pool et al., 2000; Jamrozik et al., 2001; Lidauer et al., 2000 and 2003; Samoré et al., 2002). In such a context, Jamrozik and Schaeffer (1997) reported very high heritability estimates using TDM, but negative genetic correlations among test days in early and late lactation when using Ali and Schaeffer (1987) curve to adjust the additive genetic effect, assuming the non-hereditary animal effect constant. Later, Jamrozik et al. (1997a and b), using the Wilmink (1987) curve reported 
more realistic heritability estimates at the beginning and end of lactation, indicating the importance of adequate modeling of the non-hereditary animal effect in random regression models. Brotherstone et al. (2000) reported that the parametric curves of Ali and Schaeffer (1987) and Wilmink (1987) were more adequate in adjusting the milk yields first lactation Holstein cows when compared with Legendre orthogonal polynomials.

The parametric functions of Ali and Schaeffer (1987) and Wilmink (1987) have been used in the adjustment of RRM, as they allow the modeling of the lactation curve and simultaneously characterise the covariance structure among the test day yields (Jamrozik and Schaeffer, 1997; Brotherstone et al., 2000). The implementation of RRM for genetic evaluations of dairy cattle depends on the estimates of the covariance components and genetic parameters for the traits included in the breeding program. The objective of this study is to evaluate and to compare the parametric logarithmic function proposed by Ali and Schaeffer (1987) and the exponential function proposed by Wilmink (1987) and a combination of the Legendre polynomial of second order and Wilmink function to adjust test day milk yields of first lactation Holstein cows using RRM.

\section{Material and methods}

\section{Data}

Milk yield records were obtained from the milk recording services of the Brazilian Holstein and their state affiliates from 1991 to 2001. Records originated from 39048 lactations from 531 herds located in the states of Sao Paulo, Minas Gerais, Rio Grande do Sul, Santa Catarina and Espírito Santo.

Test day records were edited for cows aged 18 to 48 months and 5 to 305 days after calving. It was required a minimum of three test day records per cow. Moreover, it was determined that each CG, defined as test herd-yearmonth of calving, included at least four records. After these edits 32448 first lactations (263390 test day records) were used in the statistical analyses. Table 1 displays number of records, animals and data structure, as well as average and standard deviations of milk yield in the test days. There was an average of eight test days per cow; and $80.85 \%$ of the cows had eight or more test days.

Table 1 Structure of the data, average $(\mathrm{kg})$ and standard deviations $(\mathrm{kg})$ of test day milk yields

\begin{tabular}{lrlr}
\hline \hline $\begin{array}{l}\text { No. of records } \\
\text { No. of animals }\end{array}$ & 263930 & No. of animals in analysis ${ }^{\dagger}$ & 49394 \\
with records & 32449 & No. of sires ${ }^{\ddagger}$ & 1955 \\
$\begin{array}{l}\text { Average } \\
\text { s.d. }\end{array}$ & 20.57 & No. of dams & \\
& 5.99 & No. of contemporary groups & 14537 \\
\hline
\end{tabular}

${ }^{\dagger}$ Including parents without records and dummy identities for unknown dams.

${ }^{\ddagger}$ With progeny in the data.

$\S$ With progeny in the data, including dummy assigned for animals with missing dam identities.
Just $9.39 \%$ of the cows presented less than five available test days.

The pedigree data included 3737 bulls and 32449 cows with records. Non-informative animals were eliminated and a total of 49394 animals were included in the A matrix.

\section{Models}

The lactation curve and covariance structure among test days were modeled by three functions.

(a) Ali and Schaeffer (1987) logarithmic function (AS):

$$
a_{0}+a_{1} c+a_{2} c^{2}+a_{3}(\ln 1 / c)+a_{4}(\ln 1 / c)^{2}
$$

where $c=D I M / 305$ and DIM $=$ days in milk.

(b) Wilmink exponential (1987) function (W):

$$
a_{0}+a_{1} t+a_{2} \exp \left(-a_{3} t\right)
$$

where $t=\mathrm{DIM}$.

(c) An alternative form of the Wilmink exponential function $\left(W^{*}\right)$ :

$$
a_{0}+a_{1} t / 100+a_{2} \exp \left(-a_{3} t\right)
$$

in which the second term is divided by 100 to reduce the amplitude of the covariate, expecting to improve the numeric properties of the model (Jakobsen et al., 2002).

(d) and a combination of parametric and non-parametric function $(L E G+W)$ :

$$
\begin{aligned}
0.7071 a_{0} & +1.2247 x a_{1}+\left(2.3717 x^{2}-0.7906\right) a_{2} \\
& +\exp \left(-a_{3} x\right)
\end{aligned}
$$

where $x=-1+2(D I M-5) /(305-5)$ and the coefficients $a_{0}-a_{2}$ are coefficients of the second order Legendre polynomial at DIM.

In the Wilmink curve, the fourth parameter $\left(a_{3}\right)$ is generally considered as a constant. In the present study it was assumed equal to -0.05 .

In its general expression, the RRM may be represented by:

$$
y_{i t}=F_{i t}+\sum_{m=0}^{f-1} \beta_{m} P_{m}(t)+\sum_{m=0}^{k-1} \alpha_{i m} P_{m}(t)+\sum_{m=0}^{k-1} \gamma_{i m} P_{m}(t)+e_{i t} .
$$

where $y_{i t}$ is the milk yield of cow $i$ on day $t, \beta_{m}$ are the coefficients of fixed regression for an average population curve; $\alpha_{i m}$ and $\gamma_{i m}$ are, respectively, the additive genetic and the non-hereditary random regression coefficients for cow $i ; e_{i t}$ is the measurement error associated to classes of time $t_{i} F_{i t}$ represent fixed effects of the model: test herd-yearmonth, season of calving, and age of the cow at calving as a co-variable with linear and quadratic terms; $P_{m}(t)$ is the $m$ th term of the adjusted function; $f$ and $k$ is the number of coefficients of the fixed and random effects of the adjusted function. Thus, for the AS curve in [1]: $P_{0}(t)=1, P_{1}(t)=c$, $P_{2}(t)=c^{2}, P_{3}(t)=\ln 1 / c, P_{4}(t)=(\ln 1 / c)^{2}$ and $f=k=5$. 
The model above can be written in matrix form as:

$$
\mathbf{y}=\mathbf{X b}+\mathbf{Z} \boldsymbol{\alpha}+\mathbf{Z}_{\mathrm{D}} \boldsymbol{\gamma}+\mathbf{e}
$$

where $\mathbf{y}$ is the test day yields vector; $\mathbf{b}$ is the vector of fixed effects; $\boldsymbol{\alpha}$ and $\boldsymbol{\gamma}$ are the vectors of random regression coefficients for the additive genetic and non-hereditary animal effects, respectively; e is the vector of residual random effect; and $\mathbf{X}, \mathbf{Z}$ and $\mathbf{Z}_{\mathbf{D}}$ are the matrices that associate the observations to the fixed effects, random animal effects and non-hereditary animal effects, respectively. Assume

$$
\left[\begin{array}{l}
\boldsymbol{\alpha} \\
\gamma \\
\mathrm{e}
\end{array}\right] \sim \mathrm{N}(\mathbf{0}, \mathbf{V}), \mathrm{V}=\left[\begin{array}{ccc}
\mathrm{G}_{\mathrm{A}} \otimes \mathrm{A} & 0 & 0 \\
0 & \mathrm{P}_{\mathrm{D}} \otimes \mathrm{I} & 0 \\
0 & 0 & \mathrm{R}
\end{array}\right],
$$

in which $G_{A}$ and $P_{D}$ are, respectively, the additive genetic and non-hereditary random regression coefficients covariance matrix effect; $\mathbf{A}$ is the relationship matrix; $\mathbf{I}$ is an identity; $\otimes$ is Kronecker product between matrices; and $\mathbf{R}=\operatorname{diag} \sigma_{\text {en }}^{2}$, in which $n$ represents number of the classes of days in milk (DIM) for adjustment of heterogeneous residual variance. Thus, for the AS curve in [1], $n=1, \ldots, 29$ for DIM: $5-20, \quad 21-30, \ldots, 295-305$; $n=1, \ldots, 4$ for DIM: $5-45,46-115,116-265$ and $266-$ 305 , and $n=1$ residual variance (RV) was assumed homogenous or constant throughout lactation. The adjusted models using the AS curve were identified as AS, followed by ME (measurement error) and the number of classes of RV $(29,4$ or 1$)$. Thus, ASME29 identifies the AS curve adjusted with 29 classes of measurement error.

The covariance components for the random effects were estimated using 'DxMRR' Meyer (1998a) with (Al)REML average information algorithm (Meyer, 1997). The convergence criterion was defined by the difference between the value of the likelihood function of consecutive iterations less than $10^{-4}$. Each analysis was repeated with estimated values from the previous analysis until the values of the likelihood function were equal for two consecutive analyses.

The evaluation of the adjusted models was accomplished by comparing the covariance components and the parameters estimated by a repeatability single character model (Melo et al., 2005). Also the following statistical criteria were used: logarithm of the maximum likelihood function $(\log \ell) ;$ the Akaike information criteria $(A I C=-2 \log \ell+2 p)$; and the Schwarz information criteria $(B I C=-2 \log e+p \log (N-r(x)))$, in which $p$ is the number of estimated parameters, $N$ is the sample size and $r(x)$ is the rank of the matrix of fixed effect coefficients in the model.

\section{Results}

The $\log \ell$ and AIC values indicate that the adjustment of the ASME29 model is superior to the other models studied, whereas for BIC, ASME1 proved to be superior to the other models (Table 2). Values obtained for $\log \ell$ and AIC tend to favour models with a greater number of parameters, whereas $\mathrm{BIC}$, which is more likely to penalise a greater number of parameters, tends to select more parsimonious models. The $\mathrm{W}$ model exhibited a convergence difficulty. This was probably due to the numeric problems that occurred in function of the amplitude of the co-variables, which was not observed using the $W^{*}$ model. The LEG $+\mathrm{W}$ model showed better results than models $\mathrm{W}$ e $W^{*}$, but inferior than the AS models.

The number of records, average and standard deviations, and the residual variance estimates for milk yields in the respective measurement error classes of DIM for the adjusted models are shown in Table 3. Only results for homogeneous residual variances are given for $L E G+W$, W e $W^{*}$ models, since differences among the residual variance estimates assuming 29 and four measurement error classes were rather small and similar to those observed for the AS model. The RV values found were 5.29, 5.56 and $5.63 \mathrm{~kg}^{2}$ for the LEG $+\mathrm{W}, \mathrm{W}$ and $\mathrm{W}^{*}$ models respectively; which were larger than $4.56 \mathrm{~kg}^{2}$ obtained for the ASME1 model (Table 3).

The RV estimates obtained for the DIM through the adjustment of the ASME29 model were similar, varying from $4.15 \mathrm{~kg}^{2}$ for ME28 to $5.11 \mathrm{~kg}^{2}$ for ME26. The average RV obtained from the 29 measurement error groups was $4.55 \mathrm{~kg}^{2}$, with a standard deviation of $0.26 \mathrm{~kg}$. RV estimates obtained through the adjustment of the ASME4 model varied from $4.78 \mathrm{~kg}^{2}$ for ME1 to $4.50 \mathrm{~kg}^{2}$ for ME2. The average RV obtained from this model was $4.59 \mathrm{~kg}^{2}$, with a standard deviation of $0.13 \mathrm{~kg}$. The RV value estimated by fitting the ASME1 model was $4.56 \mathrm{~kg}^{2}$. Overall, it was observed similar average and small variation for RV estimates among models with different measurement error indicating there is no need to fit for heterogeneity of RV.

Covariance estimates and correlations among the random regression coefficients for the additive genetic and non-hereditary animal effects of the AS curve, as well as the associated eigenvalues are displayed in Tables 4 and 5 . The estimates of the random regression coefficients for the additive genetic effect were very similar regardless of the

Table 2 Rank of the matrix of random regression coefficients for genetic additive effect $\left(k_{A}\right)$, number of parameters $(p)$, the log likelihood (loge), criteria of information of AIC and BIC for each random regression model

\begin{tabular}{lccccc}
\hline \hline Model & Rank of $k_{\mathrm{A}}$ & $p$ & $\log \ell$ & $\mathrm{AIC}^{\dagger}$ & $\mathrm{BIC}^{\dagger}$ \\
\hline ASME29 & 5 & 59 & -424543.99 & 849205.99 & 849824.39 \\
ASME4 & 5 & 34 & -424601.44 & 849270.89 & 849627.25 \\
LEG + W & 4 & 21 & -429283.53 & 858609.07 & 858829.17 \\
ASME1 & 5 & 31 & -424611.27 & 849284.54 & 849609.47 \\
W & 3 & 13 & -445036.06 & 890098.12 & 890234.38 \\
W $^{*}$ & 3 & 13 & -430912.37 & 861850.73 & 861986.99 \\
\hline \hline
\end{tabular}

${ }^{\dagger} A I C=-2 \log \ell+2 p . B I C=-2 \log \ell+p \log (N-r(x))$, in which $p$ is the number of estimated parameters, $N$ is the sample size, $r(x)$ is the matrix rank of the fixed effect coefficients in the analysis model. 
De Melo, Packer, Costa and Machado

Table 3 Days in milk (DIM), number of records (N), mean and standard deviation (s.d.) and residual variance estimates (RV) for milk yield for classes of error measurements from fitted RR models

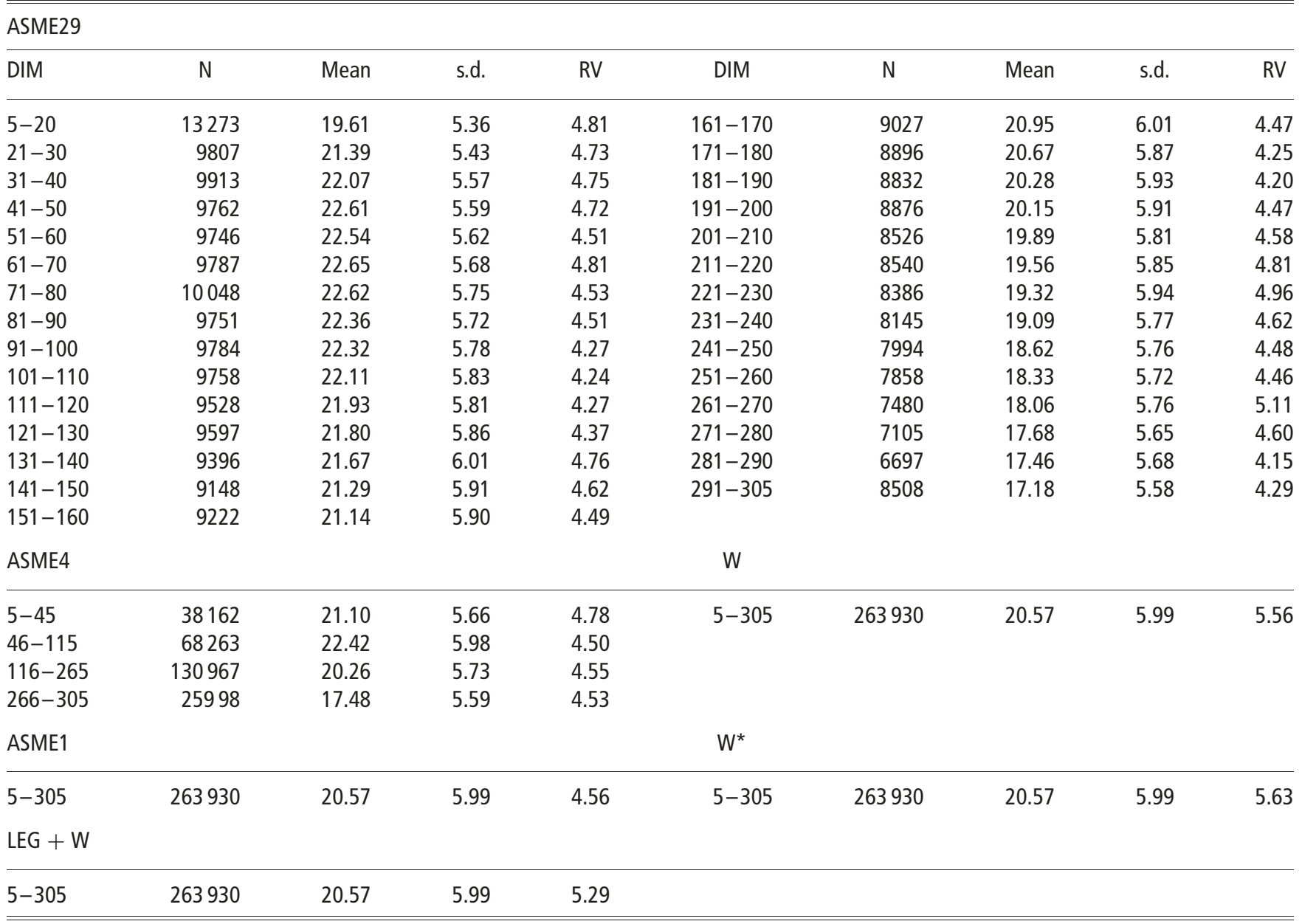

RV modeling for the AS curve. The same trend was observed for the estimates of coefficients of the non-hereditary animal effect.

Covariance estimates and correlations among the random regression coefficients in the $\mathrm{W}$ and $\mathrm{W}^{*}$ curves for the additive genetic and non-hereditary animal effects are shown in Table 6. The variance estimates were similar for coefficients $a_{0}$ and $a_{2}$ but higher for $a_{1}$ with the $W^{*}$ curve. Some differences were observed between functions regarding the magnitude and meaning of the correlations among the coefficients. This was certainly due to the scale effect related to the co-variable (t/100) associated to coefficient $a_{1}$.

The genetic variance estimates obtained from the ASME1 (Figure 1a), ASME4 (Figure 1b), ASME29 (Figure 1c), LEG + W (Figure 2) and $W^{*}$ (Figure 3a) models were similar throughout the lactation period. In the ASME1 model, the genetic variance $\left(7.59\right.$ to $\left.11.88 \mathrm{~kg}^{2}\right)$ presented an average of $8.77 \mathrm{~kg}^{2}$, with a standard deviation of $0.63 \mathrm{~kg}$ (Figure $1 \mathrm{a}$ ). However, genetic variance estimates for the $\mathrm{W}$ model exhibited a different trend, increasing from $9.47 \mathrm{~kg}^{2}$ on the fifth DIM to $171.27 \mathrm{~kg}^{2}$ at the end of lactation (Figure $3 b$ ).

Variance estimates of the non-hereditary animal effect presented a trend similar to that observed for the genetic variance estimates in the ASME1 (Figure 1a), ASME4
(Figure 1b), ASME29 (Figure 1c) and $W^{*}$ (Figure 3a) models, with the exception of an increase occurring from the 240th DIM through to the end of lactation. With respect to the $\mathrm{W}$ model, variance estimates for the nonhereditary animal effect accompanied the same trend as the estimates for the additive genetic effect, increasing from the beginning to the end of lactation (Figure $3 \mathrm{~b}$ ).

Heritability estimates did not differ among the ASME29, ASME4, ASME1 and LEG + W models (Figure 4a). The estimates decreased from 0.35 at the beginning of lactation to 0.30 on the 25th DIM and afterwards increased to 0.41 on the 234th DIM; and again decreased through to the end of lactation. Heritability estimates for the $W^{*}$ model (Figure 4b) exhibited a more stable trend, decreasing from 0.36 at the beginning of lactation to 0.33 on the 44th DIM and small increase at the end of lactation with a value of 0.40 . Heritability estimates in the W model (Figure 4c) began with a value of 0.27 and was larger than the estimates obtained from the other models, particularly at the end of lactation (0.65). The estimates for the $\mathrm{W}$ model reflected the trend of increasing genetic variance along lactation.

Genetic correlation estimates among test day yields were similar between ASME1 (Table 7), $\mathrm{W}^{*}$ (Table 8) and the LEG $+W$ models (Table 10). Estimates were close to 
Genetic parameters for test day milk yields by random regression

Table 4 Estimates of covariance and correlations between random regression coefficients of the genetic additive effect for AS models and eigenvalues $(\lambda)$ associated to matrix $\boldsymbol{k}_{\boldsymbol{A}}$

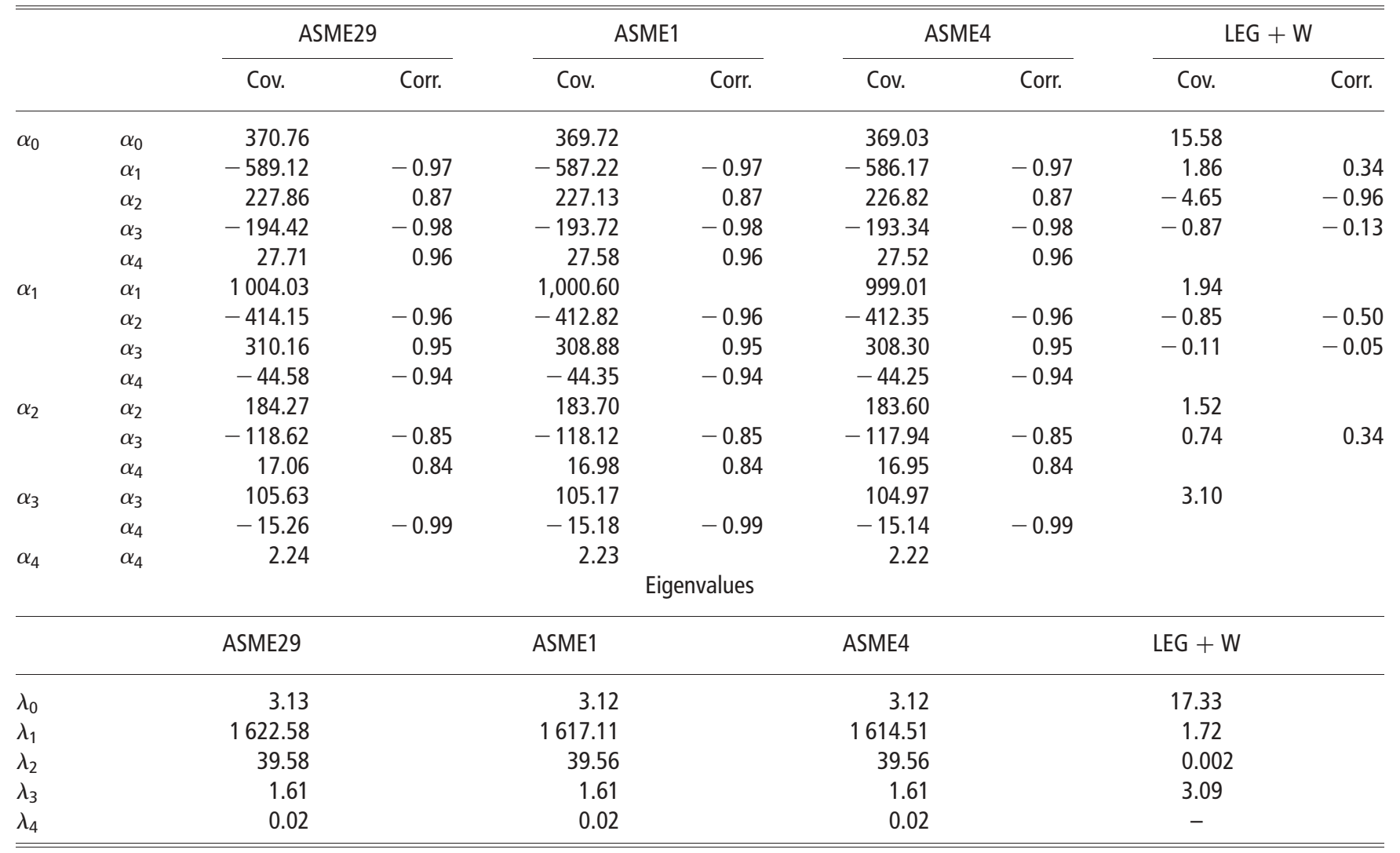

the unity for adjacent test day yields and decreased for DIM in the beginning and the end of lactation. Genetic correlation estimates were slightly higher for the ASME1 model between the beginning and mid-period of lactation, whereas this trend of higher values was observed for the $\mathrm{W}$ model among the test day yields in the intermediary phase and at the end of lactation. Genetic correlation values among the test day yields for the $W^{*}$ (Table 9) model were similar to those obtained for the other models, with the exception of negative estimates observed between test days in the beginning and end of lactation. Correlation estimates among test days non-hereditary animal effect were similar for the fitted models. Slightly higher estimates were observed for the LEG $+\mathrm{W}, \mathrm{W}$ and $W^{*}$ models. The same trend reported for genetic correlations was observed: estimates were close to the unity for adjacent test days and decreased for yields in more distant DIM along the lactation period.

\section{Discussion}

Pool and Meuwissen (1999) observed that the use of data from incomplete lactations (less than 280 days of lactation) could affect the estimate of variance components. They recommend only using data from complete lactations for estimating such parameters. However, discarding data from incomplete lactations or lactations in progress may bias the estimates of these parameters, particularly in the management of some national production systems (Costa et al., 2005), where cows with low yields may not have the same opportunity to complete lactation as cows with high yields. Thus, it was considered reasonable to use lactations from cows with at least three tests (approx. 90 days into lactation) to avoid data selection and allow more realistic estimates of the model parameters under national conditions. This decision proved to be prudent, as the residual variance estimates exhibited a tendency toward homogeneity throughout the lactation period.

With respect to model selection, AIC and BIC information criteria involved two terms: one associated to the maximum likelihood function, which measures the lack of model fitting; and another that penalises more complex models by considering the number of parameters of the model. The $\log \ell$ and AIC favour more parameterised models, whereas $B I C$, by penalising the number of parameters in the model, tends to favour more parsimonious models. Thus, the $\log \ell$ and AIC criteria indicated the ASME29 model, whereas BIC indicated ASME1 as the model with the best fit.

The W model presented convergence problems and was therefore characterised as a hard fitting model among those evaluated. The analyses were re-initiated various times using different values in order to attain the convergence criterion. Results from one analysis were rarely repeated in the following one. Thus, the results of the $W$ 
De Melo, Packer, Costa and Machado

Table 5 Estimates of covariance and correlations between the random regression coefficients of the non-hereditary animal effect for AS models and eigenvalues $(\lambda)$ associated to matrix $\boldsymbol{k}_{\boldsymbol{p}}$

\begin{tabular}{|c|c|c|c|c|c|c|c|c|c|}
\hline & & \multicolumn{2}{|c|}{ ASME29 } & \multicolumn{2}{|c|}{ ASME1 } & \multicolumn{2}{|c|}{ ASME4 } & \multicolumn{2}{|c|}{$\mathrm{LEG}+\mathrm{W}$} \\
\hline & & Cov. & Corr. & Cov. & Corr. & Cov. & Corr. & Cov. & Corr. \\
\hline \multirow[t]{5}{*}{$\gamma_{0}$} & $\gamma_{0}$ & 2592.51 & & 2534.34 & & 2527.81 & & 14.12 & \\
\hline & $\gamma_{1}$ & -4253.25 & -0.99 & -4154.92 & -0.99 & -4146.84 & -0.99 & -0.67 & -0.09 \\
\hline & $\gamma_{2}$ & 1694.03 & 0.92 & 1650.50 & 0.92 & 1649.27 & 0.92 & -3.43 & -0.48 \\
\hline & $\gamma_{3}$ & -1438.84 & -0.99 & -1406.91 & -0.99 & -1402.55 & -0.99 & 0.16 & 0.03 \\
\hline & $\gamma_{4}$ & 207.85 & 0.98 & 203.25 & 0.98 & 202.57 & 0.98 & - & - \\
\hline \multirow[t]{4}{*}{$\gamma_{1}$} & $\gamma_{1}$ & 7131.71 & & 6966.19 & & 6956.75 & & 3.41 & \\
\hline & $\gamma_{2}$ & -2943.20 & -0.97 & -2870.57 & -0.97 & -2869.76 & -0.97 & 0.20 & 0.06 \\
\hline & $\gamma_{3}$ & 2341.08 & 0.97 & 2286.91 & 0.97 & 2281.40 & 0.97 & 0.19 & 0.08 \\
\hline & $\gamma_{4}$ & -335.57 & -0.95 & -327.73 & -0.95 & -326.88 & -0.95 & - & - \\
\hline \multirow[t]{3}{*}{$\gamma_{2}$} & $\gamma_{2}$ & 1296.07 & & 1264.84 & & 1265.54 & & 3.65 & \\
\hline & $\gamma_{3}$ & -916.19 & -0.89 & -892.01 & -0.89 & -891.03 & -0.89 & -0.34 & -0.14 \\
\hline & $\gamma_{4}$ & 129.33 & 0.86 & 125.79 & 0.86 & 125.64 & 0.86 & - & - \\
\hline \multirow[t]{2}{*}{$\gamma_{3}$} & $\gamma_{3}$ & 809.90 & & 792.43 & & 789.54 & & 1.65 & \\
\hline & $\gamma_{4}$ & -118.08 & -1.00 & -115.58 & -1.00 & -115.13 & -1.00 & - & - \\
\hline \multirow[t]{3}{*}{$\gamma_{4}$} & $\gamma_{4}$ & 17.37 & & 17.01 & & 16.94 & & - & \\
\hline & \multicolumn{9}{|c|}{ Eigenvalues } \\
\hline & & ASME29 & & ASME1 & & ASME4 & & $\mathrm{LEG}+\mathrm{W}$ & \\
\hline$\lambda_{0}$ & & 3.93 & & 3.92 & & 3.93 & & 15.20 & \\
\hline$\lambda_{1}$ & & 11674.30 & & 11400.00 & & 11383.10 & & 3.40 & \\
\hline$\lambda_{2}$ & & 162.65 & & 163.69 & & 162.97 & & 2.70 & \\
\hline$\lambda_{3}$ & & 6.60 & & 6.59 & & 6.58 & & 1.55 & \\
\hline$\lambda_{4}$ & & 0.04 & & 0.04 & & 0.04 & & - & \\
\hline
\end{tabular}

curve should be viewed with caution. The results obtained from the $\mathrm{W}^{*}$ model, however, were consistent, demonstrating that the division of the covariate by 100 was effective in circumventing problems of instability in the estimation of random regression coefficients.

These results are in agreement with those obtained by Schaeffer and Guo (2002). They evaluated different models (but not the $\mathrm{W}^{*}$ model, as suggested by Jakobsen et al., 2002) and conclude that the AS model was superior to the
W model, which was one of the three worst fitted models. In the present study, the $W^{*}$ model proved to be computationally efficient, as it did not present convergence problems.

Differently from observations in other studies (Olori et al., 1999; Rekaya et al., 1999; Brotherstone et al., 2000; Jamrozik et al., 2001; Lopez-Romero and Carabaño, 2003), in which higher RV estimates were obtained for the beginning and end of lactation, RV estimates in the present study were similar among the DIM classes, as well as

Table 6 Estimates of variance (diagonal), covariance (below the diagonal) and correlations (above the diagonal) between random regression coefficients for the $W$ and $W^{*}$ models and eigenvalues $(\lambda)$ associated to $k_{A}$ and $k_{p}$, respectively the additive genetic and non-hereditary animal effects

\begin{tabular}{|c|c|c|c|c|c|c|c|}
\hline \multicolumn{4}{|c|}{ W } & \multicolumn{4}{|c|}{$W^{*}$} \\
\hline \multicolumn{4}{|c|}{ Genetic additive effect } & \multicolumn{4}{|c|}{ Genetic additive effect } \\
\hline$\alpha_{0}$ & $\alpha_{1}$ & $\alpha_{2}$ & $\lambda$ & $\alpha_{0}$ & $\alpha_{1}$ & $\alpha_{2}$ & $\lambda$ \\
\hline 10.72 & -0.220 & -0.65 & 5.085 & 10.93 & -0.49 & -0.46 & 8.08 \\
\hline-0.03 & 0.002 & 0.15 & 0.002 & -1.80 & 1.22 & -0.13 & 0.68 \\
\hline-10.73 & 0.034 & 25.50 & 31.140 & -7.64 & -0.70 & 24.77 & 28.16 \\
\hline \multicolumn{4}{|c|}{ Non-hereditary animal effect } & \multicolumn{4}{|c|}{ Non-hereditary animal effect } \\
\hline$\gamma_{0}$ & $\gamma_{1}$ & $\gamma_{2}$ & $\lambda$ & $\gamma_{0}$ & $\gamma_{1}$ & $\gamma_{2}$ & $\lambda$ \\
\hline 15.10 & -0.360 & -0.45 & 10.783 & 16.49 & -0.75 & -0.54 & 10.67 \\
\hline-0.05 & 0.001 & 0.19 & 0.001 & -5.09 & 2.81 & 0.46 & 1.12 \\
\hline-10.37 & 0.037 & 35.70 & 40.018 & -13.64 & 5.08 & 38.90 & 46.40 \\
\hline
\end{tabular}



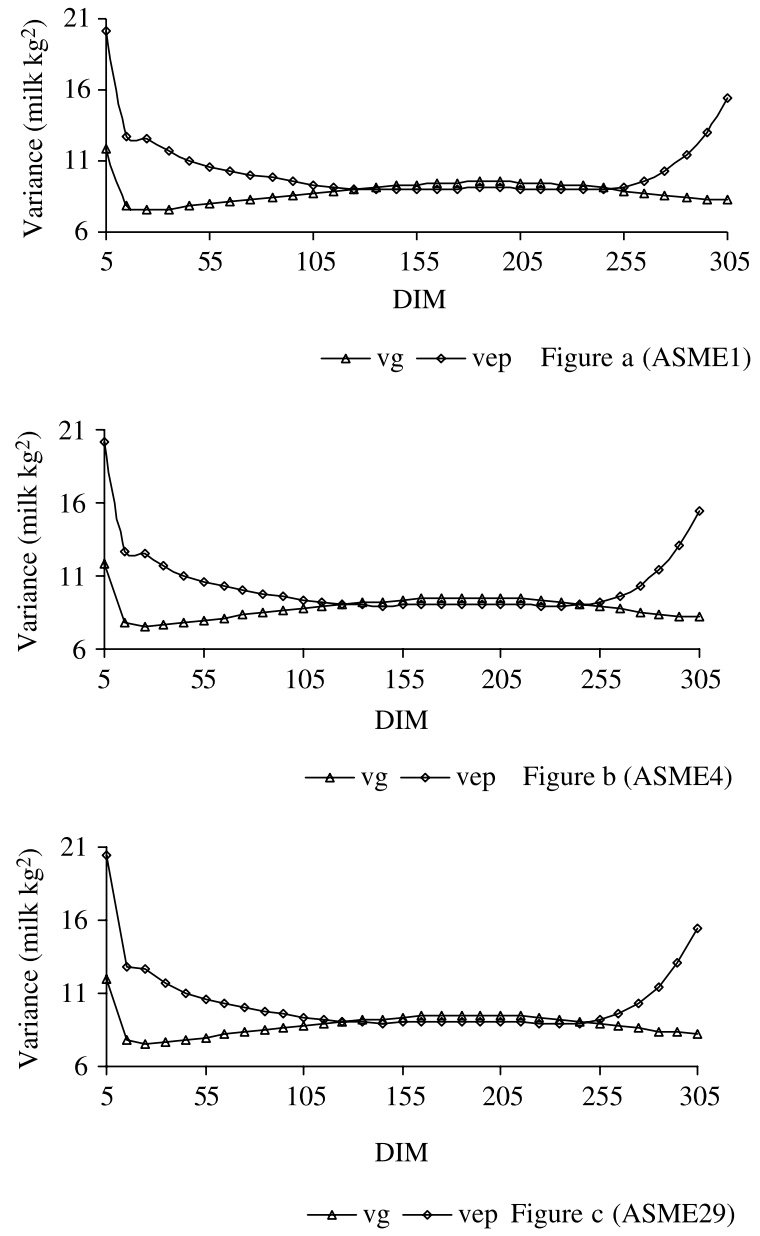

Figure 1 Estimates of genetic (vg) and non-hereditary (vep) variances obtained by fitting the models ASME1 (Figure a), ASME4 (Figure b) and ASME29 (Figure c).

among the fitted models. Thus, assuming RV homogeneity does not appear to compromise the accuracy of the estimates of the other variance components and genetic parameters (Tables 3, 4 and 5). Lopez-Romero and Carabaño (2003) concluded that RV homogeneity could be assumed in the interval between 75 and 275 days of lactation, but that RV heterogeneity should be assumed outside of this interval, that is, a RV should be considered for each DIM outside this interval. However, considering a RV for each

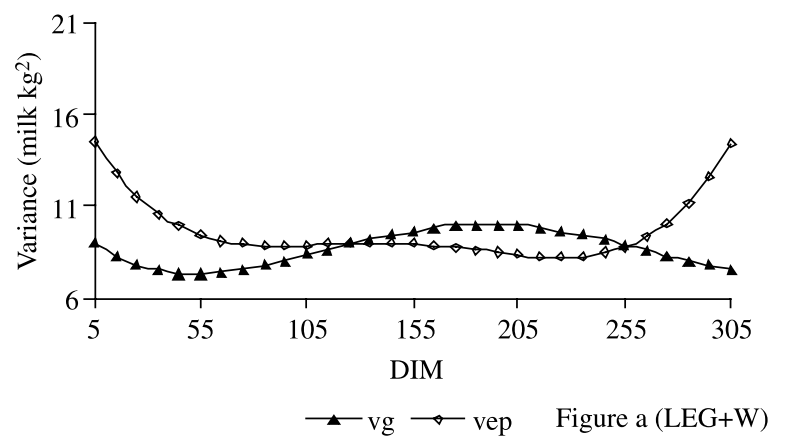

Figure 2 Estimates of genetic (vg) and non-hereditary (vep) variances obtained by fitting the model LEG + W (Figure a).
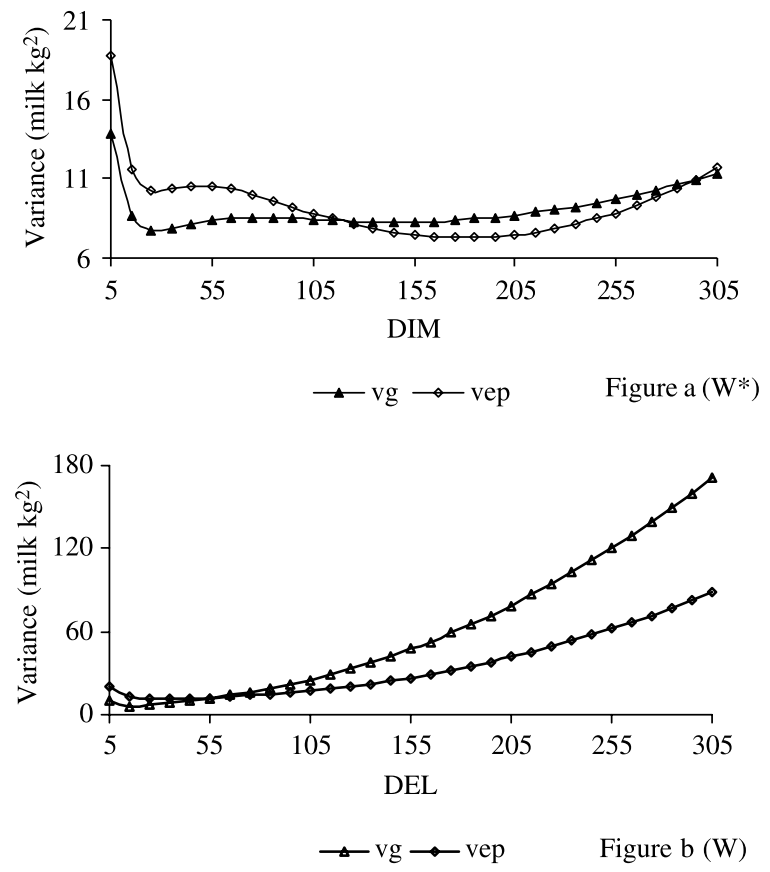

Figure 3 Estimates of genetic (vg) and non-hereditary (vep) variances obtained by fitting the models $\mathrm{W}^{*}$ (Figure a) and W (Figure b).

DIM means an overparameterised model and significantly hinders the estimation of the variance components.

Similar trends for variance estimates of genetic and permanent effects throughout the lactation were observed among the ASME1 (Figure 1a), ASME4 (Figure 1b), ASME29 (Figure 1c), LEG $+\mathrm{W}$ (Figure 2) and $\mathrm{W}^{*}$ (Figure $3 \mathrm{a}$ ) models. Estimates decreased from the beginning of lactation to more stable values through to the final third of lactation, when values increased. Estimates obtained from the $\mathrm{W}$ model (Figure $3 \mathrm{~b}$ ) increased from the beginning to the end of lactation, when they reached markedly elevated values in comparison to the estimates obtained from the other models. These results differ from those reported by Jamrozik et al. (1997b), who obtained similar results using both the AS and the W curve and from those from Jamrozik et al. (1997a), who described a reduction in genetic variance from the beginning to the 25th day of lactation and then stability in values through to the end of lactation when using the $W$ model.

Heritability estimates did not differ among the ASME1, ASME4, ASME29 and LEG + W models (Figure 4a), ranging between 0.30 and 0.41 . After a decrease at the beginning, there was an increase that resulted in higher values at mid lactation and another decrease toward lower values at the end of lactation. The heritability estimates for the $\mathrm{W}^{*}$ model (Figure $4 \mathrm{~b}$ ) exhibited a more stable trend, decreasing from 0.36 at the beginning of lactation to 0.33 on the 44th DIM. A slight increase was observed at the end of lactation, when heritability estimates reached the value 0.40 . Olori et al. (1999) reported similar trends when fitting a quadratic polynomial curve. With respect to the convergence problems observed, heritability estimates in the $\mathrm{W}$ model (Figure 4c) were higher than those obtained from the other models (except at the beginning of 
De Melo, Packer, Costa and Machado

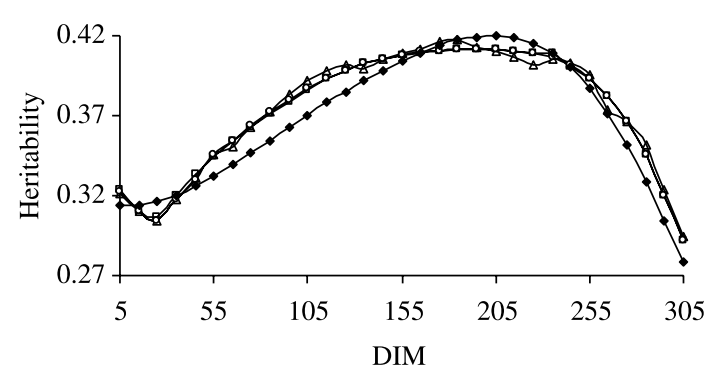

$\rightarrow$ ASME $1 \multimap$ ASME $29 \multimap$ ASME $4 \multimap$ LEG+W Figure a

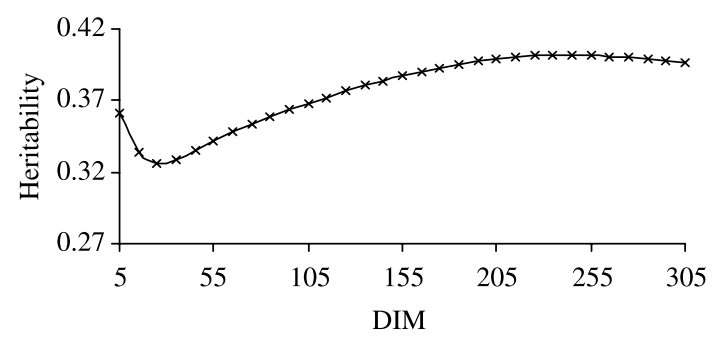

$\rightarrow-\mathrm{W}^{*}$

Figure b

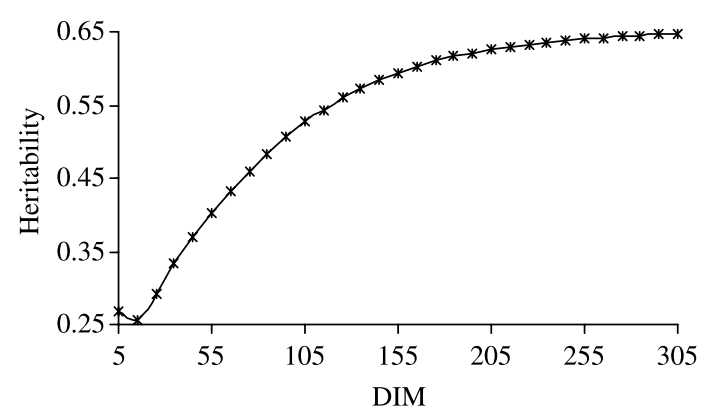

$\rightarrow-\mathrm{W}$

Figure c

Figure 4 Estimates of heritability obtained by fitting the models ASME29, ASME4, ASME1 and LEG + W (Figure a), W* (Figure b) and W (Figure c).

lactation). Starting from 0.27 at the beginning of lactation, the estimates increased continually until reaching 0.65 by the end of the period. This trend was similar to that observed by Brotherstone et al. (2000), who, however, reported lower heritability estimates (0.08 to 0.24 ).

Table 7 Estimates of heritability (diagonal), genetic (below the diagonal) and non-hereditary correlations (above the diagonal) between test-day milk yields for selected days in milk (DIM) using the ASME1 model

\begin{tabular}{lcccccccc}
\hline \hline DIM & 5 & 25 & 45 & 125 & 165 & 265 & 285 & 305 \\
\hline 5 & 0.32 & 0.74 & 0.63 & 0.30 & 0.17 & 0.06 & 0.08 & 0.11 \\
25 & 0.29 & 0.30 & 0.96 & 0.70 & 0.60 & 0.47 & 0.46 & 0.45 \\
45 & 0.37 & 0.94 & 0.33 & 0.85 & 0.76 & 0.62 & 0.61 & 0.60 \\
125 & 0.37 & 0.64 & 0.79 & 0.40 & 0.98 & 0.89 & 0.86 & 0.82 \\
165 & 0.24 & 0.56 & 0.65 & 0.95 & 0.41 & 0.95 & 0.92 & 0.87 \\
265 & 0.06 & 0.40 & 0.42 & 0.58 & 0.71 & 0.37 & 0.99 & 0.97 \\
285 & 0.08 & 0.33 & 0.37 & 0.44 & 0.54 & 0.97 & 0.35 & 0.99 \\
305 & 0.10 & 0.25 & 0.30 & 0.29 & 0.34 & 0.87 & 0.97 & 0.29 \\
\hline \hline
\end{tabular}

Table 8 Estimates of heritability (diagonal), genetic (below the diagonal) and non-hereditary correlations (above the diagonal) between test-day milk yields for selected days in milk (DIM) using the W model

\begin{tabular}{lcccccccc}
\hline \hline DIM & 5 & 25 & 45 & 125 & 165 & 265 & 285 & 305 \\
\hline 5 & 0.27 & 0.63 & 0.36 & 0.16 & 0.13 & 0.08 & 0.08 & 0.07 \\
25 & 0.78 & 0.29 & 0.94 & 0.67 & 0.56 & 0.39 & 0.37 & 0.35 \\
45 & 0.54 & 0.95 & 0.37 & 0.83 & 0.73 & 0.56 & 0.53 & 0.51 \\
125 & 0.30 & 0.71 & 0.85 & 0.56 & 0.99 & 0.92 & 0.91 & 0.90 \\
165 & 0.24 & 0.57 & 0.71 & 0.97 & 0.60 & 0.97 & 0.97 & 0.96 \\
265 & 0.11 & 0.29 & 0.42 & 0.83 & 0.94 & 0.64 & 1.00 & 1.00 \\
285 & 0.09 & 0.25 & 0.38 & 0.81 & 0.92 & 1.00 & 0.64 & 1.00 \\
305 & 0.08 & 0.22 & 0.34 & 0.78 & 0.90 & 1.00 & 1.00 & 0.65 \\
\hline \hline
\end{tabular}

Estimates obtained from the ASME1, ASME4, ASME29, $\mathrm{LEW}+\mathrm{W}$ and $\mathrm{W}^{*}$ models were the most similar to the estimates obtained by Melo et al. (2005). Their estimates for test day yields from single-character analyses ranged from 0.22 to 0.36 . These estimates are a reference (Rekaya et al., 1999) to characterise an expected value for the heritability estimates from TDM throughout the lactation period.

Genetic correlation estimates among test day yields were similar between the ASME1 (Table 7) and W models (Table 8). Estimates were close to the unity for adjacent test day yields but decreased to lower values for yields between the beginning and end of lactation. Genetic correlation estimates were slightly higher for the ASME1 model between the beginning and mid lactation periods, whereas this trend toward higher values was observed for the $\mathrm{W}$ model between test day yields from the intermediary phase and the end of lactation. Overall, these results were similar to those reported in other studies (Jamrozik and Schaeffer, 1997; Brotherstone et al., 2000; Jakobsen et al., 2002; Costa et al., 2005).

Genetic correlation estimates among test day yields for the $\mathrm{W}^{*}$ model were similar to those obtained from the other models, except for the negative values observed between test days in the beginning and end of lactation (Table 9). Similar results were reported in other studies (Rekaya et al., 1999; Brotherstone et al., 2000).

Table 9 Estimates of heritability (diagonal), genetic (below the diagonal) and non-hereditary correlations (above the diagonal) between test-day milk yields for selected days in milk (DIM) using the $W^{*}$ model

\begin{tabular}{lcccccccr}
\hline \hline DIM & 5 & 25 & 45 & 125 & 165 & 265 & 285 & \multicolumn{1}{c}{305} \\
\hline 5 & 0.36 & 0.74 & 0.48 & 0.19 & 0.11 & -0.10 & -0.13 & -0.17 \\
25 & 0.74 & 0.33 & 0.94 & 0.77 & 0.69 & 0.44 & 0.38 & 0.34 \\
45 & 0.50 & 0.95 & 0.34 & 0.93 & 0.87 & 0.64 & 0.60 & 0.55 \\
125 & 0.36 & 0.84 & 0.93 & 0.38 & 0.99 & 0.87 & 0.84 & 0.81 \\
165 & 0.34 & 0.75 & 0.83 & 0.97 & 0.39 & 0.94 & 0.91 & 0.89 \\
265 & 0.23 & 0.37 & 0.41 & 0.69 & 0.84 & 0.40 & 1.00 & 0.99 \\
285 & 0.20 & 0.29 & 0.33 & 0.62 & 0.78 & 1.00 & 0.40 & 1.00 \\
305 & 0.18 & 0.22 & 0.25 & 0.55 & 0.73 & 0.99 & 1.00 & 0.40 \\
\hline \hline
\end{tabular}


Table 10 Estimates of heritability (diagonal), genetic (below the diagonal) and non-hereditary correlations (above the diagonal) between test-day milk yields, for selected days in milk (DIM) using the $L E G+W$ model

\begin{tabular}{lcccccccc}
\hline \hline DIM & 5 & 25 & 45 & 125 & 165 & 265 & 285 & 305 \\
\hline 5 & 0.31 & 0.98 & 0.92 & 0.56 & 0.43 & 0.30 & 0.30 & 0.30 \\
25 & 0.98 & 0.32 & 0.98 & 0.71 & 0.60 & 0.46 & 0.45 & 0.43 \\
45 & 0.93 & 0.98 & 0.33 & 0.84 & 0.75 & 0.61 & 0.58 & 0.54 \\
125 & 0.54 & 0.69 & 0.82 & 0.39 & 0.99 & 0.89 & 0.84 & 0.77 \\
165 & 0.41 & 0.57 & 0.71 & 0.98 & 0.41 & 0.94 & 0.90 & 0.83 \\
265 & 0.31 & 0.37 & 0.43 & 0.61 & 0.72 & 0.37 & 0.99 & 0.97 \\
285 & 0.30 & 0.33 & 0.35 & 0.45 & 0.56 & 0.98 & 0.33 & 0.99 \\
305 & 0.29 & 0.28 & 0.27 & 0.29 & 0.40 & 0.92 & 0.98 & 0.28 \\
\hline \hline
\end{tabular}

The present study was focused on the evaluation of the parametric functions of Ali and Schaeffer and Wilmink and a combination of Legendre and Wilmink function, but other studies report satisfactory results obtained from using the Legendre orthogonal polynomials to fit random regression models (Olori et al., 1999; Brotherstone et al., 2000; Pool et al., 2000). Brotherstone et al. (2000) observed that parametric functions resulted in higher values for the maximum likelihood functions, but produced negative genetic correlations between test days in the beginning and end of lactation, which were not observed when using Legendre polynomials. The authors suggest that in situations where there are no computational limits, polynomials of a higher order are more efficient. They also suggest that a combination of parametric and non-parametric functions (Lidauer et al., 2000 and 2003) would possibly improve the modeling of the genetic and permanent environment variance components. This was not confirmed in the present study because the performance of the LEG $+W$ model was worse than the AS models.

\section{Conclusions}

The AS models evaluated in the present study exhibited similar results for residual and genetic variances. Heritability estimates for test day milk yields were close to the values obtained from single-trait analyses and of similar magnitude to results found in the literature.

The model based on the Wilmink curve presented convergence problems. Its variation, the $\mathrm{W}^{*}$ model, resulted in negative genetic correlation estimates between test days yields in the extremes of the lactation. The LEG $+W$ model did not show any improvement over the AS models.

The ASME1 was characterised as the most parsimonious and of lower computational demand to model test day milk yields of Holstein cows in Brazil by RRM.

\section{Acknowledgements}

This work was supported by Prodetab/Embrapa Project 05402/99 and by FAPESP Process 99/03 838-6. Data were provided by $A B C B R H$ (Holstein Brazilian Association). The first author is supported by a scholarship of the FAPESP.

\section{References}

Albuquerque LG and Meyer K 2005. Estimates of covariance functions for growth of Nelore cattle applying a parametric correlation structure to model within-animal correlations. Livestock Production Science 93, 213-222.

Ali TE and Schaeffer LR 1987. Accounting for covariances among test day milk yields in dairy cows. Canadian Journal of Animal Science 67, 637-644.

Brotherstone S, White IMS and Meyer K 2000. Genetic modeling of daily milk yield using orthogonal polynomial and parametric curves. Animal Science 70, 407-415.

Costa CN, Melo CMR, Machado CHC, Freitas AF, Packer IU and Cobucci JA 2005. Parâmetros genéticos para a produção de leite de controles individuais de vacas da raça Gir estimados com modelos de repetibilidade e regressão aleatória. Revista Brasileira de Zootecnia 34, 1520-1531.

Fischer TM, Van der Werf JHJ, Banks RG and Ball AJ 2004. Description of lamb growth using random regression on field data. Livestock Production Science 89, 175-185.

Gengler N, Tijani A, Wiggans GR and Misztal I 1999. Estimation of (co)variance function coefficients for test day yield with a Expectation-Maximization Restricted Maximum Likelihood Algorithm. Online. (1999). Available: http:// 12.24.208.139/manuscrits/843e/.

Jakobsen JH, Madsen $\mathrm{P}$, Jensen J, Pedersen J, Christensen LG and Sorensen DA 2002. Genetic parameters for milk production and persistency for Danish Holsteins estimated in random regression models using REML. Journal of Dairy Science 85, 1607-1616.

Jamrozik J, Gianola D and Schaeffer LR 2001. Bayesian estimation of genetic parameters for test day records in dairy cattle using linear hierarchical models. Livestock Production Science 71, 223-240.

Jamrozik J, Kistemaker GJ, Dekkers JCM and Schaeffer LR 1997a. Comparison of possible covariates for use in a random regression model for analyses of test day yields. Journal of Dairy Science 80, 2550-2556.

Jamrozik J and Schaeffer LR 1997. Estimates of genetic parameters for a test day model with random regressions for yield traits of first lactation Holsteins. Journal Dairy Science 80, 762-770.

Jamrozik J, Schaeffer LR and Dekkers JCM 1997b. Genetic evaluation of dairy cattle using test day yields and random regression model. Journal of Dairy Science 80, 1217-1226.

Jensen J 2002. Genetic evaluation of dairy cattle using test-day models. Journal of Dairy Science 84, 2803-2812.

Kettunen A, Mäntysaari EA and Pösö J 2000. Estimation of genetic parameters for daily milk yield of primiparous Ayrshire cows by random regression test-day models. Livestock Production Science 66, 251-261.

Lidauer M, Mäntysaari EA and Strandén I 2003. Comparison of test-day models for genetic evaluation of productions traits in dairy cattle. Livestock Production Science 79, 73-86.

Lidauer MEA, Mäntysaari AE, Strandén I and Pösö J 2000. Multiple-trait random regression test-day model for all lactations. INTERBULL Open Meeting, Bled, Slovenia, pp. 81-86.

Lopez-Romero P and Carabaño MJ 2003. Comparing alternative random regression models to analyse first lactation daily milk yield data in HolsteinFriesian cattle. Livestock Production Science 82, 81-96.

Melo CMR, Costa CN, Packer UI and Machado PF 2005. Parâmetros genéticos para as produções de leite no dia do controle e da primeira lactação de vacas da raça Holandesa. Revista Brasileira de Zootecnia 34, 796-806.

Meyer K 1997. An "average information" restricted maximum likelihood algorithm for estimating reduced rank genetic matrices or covariance functions for animal models with equal design matrices. Genetics Selection Evolution 29, 97-116.

Meyer K 1998a. "DXMRR" - A program to estimate covariance functions for longitudinal data by restricted maximum likelihood In Proceedings of the sixth world congress of genetics applied to livestock production, Armidale, Australia. CD-ROM.

Meyer K 1998b. Modeling 'repeated' records: covariance functions and random regression models to analysis animal breeding data. In Proceedings of the sixth world congress of genetics applied to livestock production, Armidale, Australia. CD-ROM.

Misztal I, Strabel T, Jamrozik J, Mäntysaari EA and Meuwissen THE 2000. Strategies for estimating the parameters needed for different test-day models. Journal of Dairy Science 83, 1125-1134. 


\section{De Melo, Packer, Costa and Machado}

Mrode RA and Swanson GJT 2004. Calculating cow and daughter yield deviations and partitioning of genetic evaluations under a random regression model. Livestock Production Science 86, 253-260.

Olori VE, Hill WG, McGuirk BJ and Brotherstone S 1999. Estimating variance e components for test day milk records by restricted maximum likelihood with a random regression animal model. Livestock Production Science 61, 53-63.

Pool MH, Janss LLG and Meuwissen THE 2000. Genetic parameters of Legendre polynomials for first parity lactation curves. Journal of Dairy Science 83, 2640-2649.

Pool MH and Meuwissen THE 1999. Prediction of daily milk yields from a limited number of test days using test day models. Journal of Dairy Science 82, 1555-1564.

Rekaya R, Carabaño MJ and Toro MA 1999. Use de test day yields for the genetic evaluation of production traits in Holstein-Friesian cattle. Livestock Production Science 57, 203-217.

Samoré AB, Boettcher P, Jamrozik J, Bagnato A. and Groen AF 2002. Genetic parameters for production traits and somatic cell scores estimated with a multiple trait random regression model in Italian Holsteins. In Proceedings of the seventh world congress of genetics applied to livestock production, Montpellier, France. CD-ROM.

Schaeffer LR 2004. Application of random regression models in animal breeding. Livestock Production Science 86, 35-45.

Schaeffer LR and Guo Z 2002. Random regression submodel comparison. In Proceedings of the seventh world congress of genetics applied to livestock production, Montpellier, France. CD-ROM.

Schaeffer LR, Jamrozik J, Kistemaker GJ and Van Doormaal BJ 2000. Experience with a test-day model. Journal of Dairy Science 83, 1135-1144.

Swalve $\mathrm{HH}$ 2000. Theoretical basis and computational for different test-day genetic evaluation methods. Journal of Dairy Science 83, 1115-1124.

Swalve HH 1998. Use of test day records for genetic evaluation. In Proceedings of the sixth world congress of genetics applied to livestock production, Armidale, Australia. CD-ROM.

Wilmink JBM 1987. Efficiency of selection for different cumulative milk, fat, and protein yields in first lactation. Livestock Production Science 17, 211-224. 